\title{
When Children Do Science: Collaborative Interactions in Preschoolers' Discussions About Animal Diversity
}

Published online: 12 February 2019

\author{
Johanna Frejd ${ }^{1}$ \\ Published online: 12 February 2019 \\ (C) The Author(s) 2019
}

\begin{abstract}
With the aim of exploring how science is done in collaborative interactions when children discuss reasons for animal diversity, this paper provides insight into the relationships between acts of doing science and collaborative interactions. Video data from four small-group discussions $(N=14)$ were analysed using Lemke's (1990) talking science framework and Granott's (1993) collaborative interaction framework. During their interactions, the children make use of their prior experiences and the materials provided as they engage in acts of doing science. The findings reveal that 6 -year-old children are able to engage in science dialogue as they use observations and comparisons as data to generate, describe and discuss ideas. Moreover, while engaged in highly collaborative interactions, the children use observations to evaluate, challenge and question each other. Overall, the study sheds light on how acts of doing science can be perceived in young students' discussions about science phenomena. The study indicates that the character of the collaborative interactions is an important factor for how acts of doing science are carried out.
\end{abstract}

Keywords Early childhood · Biology $\cdot$ Group discussion $\cdot$ Interaction $\cdot$ Multimodality

\section{Introduction}

Science can be seen as a human activity that is constructed through and during interactions between people and materials (Ash 2004). Roth and Lawless (2002), among other scholars, recognise science as a form of culture with its own narrative forms, material practices and beliefs. Hence, science education and learning science are, at least to some extent, about letting children participate in particular practices of science culture (Lemke 1990; Roth and Lawless 2002). For example, in preschool, children perform inquiries (Howitt et al. 2011) and experiments (Andersson and Gullberg 2014), they discuss ideas and problems related to

Johanna Frejd

johanna.frejd@liu.se

1 Department of Social and Welfare Studies, Linköping University, 60174 Norrköping, Sweden 
science (Osborne 2010) and engage in scientific playworlds (Fleer 2017) where the teacher engages in children's play, and play-based settings to learn science. Activities related to science in school can be labelled as doing science.

The aim of this study is to explore how children do science in collaborative interactions when they discuss ideas about the underlying reasons for animal diversity. The participating children have not undertaken any formal instruction on evolution. The example used to illustrate animal diversity in this study is big cats. Thus, even though animal diversity as a scientific phenomenon is unknown to the children, the animals used as examples in their discussions are familiar. Hence, animal diversity was believed to be a topic that, together with teaching materials such as figurines and a map, provided a relevant context for children's meaning-making. In preschool classes, which is the context for the current study, small-group discussions are common, both in free play and during structured activities. By studying small groups discussing reasons for animal diversity, we could get insight into how science is done in interaction when children become acquainted with a new topic, and how interaction affects the process of doing science.

\section{Doing Science}

Science "emerges from 'doing"' (Siry et al. 2012, p. 313) and, while doing science, understanding is talked into being (Ash 2004; Gallas 1995; Lemke 1990). Doing science is thus both a collaborative act and a social process whereby children's understandings are generated and expressed in interaction (Siry et al. 2012).

Science involves more than just learning facts and theories (Yoon and Onchwari 2006). In preschool, children often do science in playful settings. Previous studies have shown, for example, that children learn about sound (Larsson 2013) and shadows (Herakleioti and Pantidos 2016) through the use of their own bodies. Moreover, in inquiry, 5-6-year-old children can discuss and explore water as a scientific phenomenon. For example, children talk about objects "swimming" and "going to the bottom", as a way to describe whether an object floats or sinks when engaged in float and sink activities (Siry et al. 2012). Howitt et al. (2011) have also revealed that 4- to 5-year-olds generate questions and predictions, observe and record data, and use observations as evidence when engaged in inquiry framed as a forensic bear hunt.

Another context for doing science is discussions. A scholar that early on used the phrase doing science is Lemke (1990). He also used the phrase talking science inter-changeably with doing science. Doing science includes several acts. Lemke mentions acts such as observing, describing, comparing, discussing, questioning, challenging, and evaluating (cf. JimenezAleixandre et al. 2000).

Even though argumentative practices are part of science culture (Osborne 2010), engaging students in activities that stimulate discussion is rare, according to Jimenez-Aleixandre et al. (2000). In addition, previous research by Ødegaard et al. (2016) has shown that little teacherled dialogue in 14- to 15-year-olds' science classrooms actually concerns doing science in terms of description, explanation or generalisation. However, Ødegaard et al. emphasise that teacher-led dialogues often have a science focus. For example, a teacher in their study asked questions such as "What holds your body upright?" when talking about skeletons. Even if the question is not an example of science talk, in terms of description, generalisation or explanation, it is still relevant in relation to the context of the lesson. 
That teachers have an impact on science discussions is shown by Hogan et al. (1999). They studied the relationship between sophistication and complexity in scientific reasoning in small groups discussing ideas about the nature of matter. Their results revealed a difference between teacher-led groups and peer groups. Teacher-led groups were more efficient, meaning that the group more quickly reached a satisfactory resolution of ideas. However, peer groups generally scored higher, meaning that they generated more ideas, evaluated ideas more and provided more justifications for their ideas compared to the students in the teacher-led groups. One explanation for this could be that "the social structure of peer groups was more conductive to idea generation and elaboration as well as to the justifications of ideas" (p. 425). In teacher-led groups, the tone was more formal and the students waited to be addressed before talking, which could have restricted the generation of ideas. Students' contributions to the dialogue merely focused on conceptual aspects of science. According to Hogan et al., this reflects the notion of the teacher as the one who asks questions and the students as the ones who answer. Nevertheless, in preschool contexts, Sylva et al. (2004) have shown that teachers interact with children, creating sustained shared thinking. Sustained shared thinking means that the interacting people actively contribute to think about an idea, define a concept or extend a narrative, which develops and extends the understanding. However, this is most common when children (3-5 years old) interact 1:1 with an adult.

In line with science being a form of culture, school can also be seen as its own culture, with both implicit and explicit rules (Jimenez-Aleixandre et al. 2000). For example, 14- to 15-yearolds have already been attending school for several years and have "learned" how to behave in discussions in a classroom context. Having the notion that the teacher is the one who asks the questions then, of course, could have an impact on students' actions during discussions (Hogan et al. 1999). The context of the present study is preschool class. In this context, it might be possible to establish other ways of "doing school". In other words, science might be done in a different way among children of this age than among adolescents.

Collaborative work is an important part of doing science. Work in small-group situations and whole-class contexts enables the sharing of ideas. As a consequence, children may build upon a posed idea and help scaffold one another's ideas (Murphy et al. 2011). Depending on how an idea is received by the interlocutors, it can either be neglected, judged as unreliable or included in the knowledge base of the group (Kolstø and Ratcliffe 2008). Thus, when discussing in small groups, participants' previous actions, both verbal and gestural, made by themselves or by others, can together be used as building blocks to further their common meaning-making (Granott 1998) and the joint activity of doing science.

Collaborative interactions can be carried out in several ways. Ideas can be coconstructed through the integration of ideas (Mueller 2009), through confrontation (Jimenez-Aleixandre et al. 2000) or as a result of trying to reach consensus (Naylor et al. 2007). One thing that seems to have an impact on peer groups is the ability to engage in productive dialogue (Hogan et al. 1999). According to Hogan et al., more productive groups share and present ideas, ask clarification questions and interpret each other's ideas. Less productive groups spend much more time off task: joking, being sarcastic or talking about other things than the task.

In summary, we know that preschool children engage in doing science via hands-on activities. According to Ødegaard et al. (2016), the most prominent feature of classroom science talk is describing natural phenomena. Nevertheless, it seems that some types of science dialogue, such as discussing and evaluating ideas, are rare among 14- to 16-year-old students. We also know that interaction, social structure and teachers are important for students' science 
discussions. Small-group discussions might provide a context for various acts of doing science. However, we do not know how acts of doing science are carried out when preschool children engage in group discussions about a science topic in which they have not had any formal instruction. In addition, we do not know whether certain acts of doing science are more foregrounded in different types of collaborative interactions. Therefore, this study explores how children do science in collaborative interactions when they discuss reasons for animal diversity. The specific aim of the study is to characterise relationships between acts of doing science and collaborative interactions.

\section{Methods}

\section{A Multimodal Approach to Studying Acts of Doing Science in Discussions}

In general, this study takes a multimodal approach (Jewitt et al. 2001; Kress and van Leeuwen 2006), viewing language as holistic (Roth 2005). When we talk, we express ourselves not only verbally, but also through other modes of communication, such as gestures, gaze, and through pictorial/drawing modes. What we express in any mode is always intertwined with what we express in other modes in an interaction within a particular context (Goodwin 2000; Jewitt 2011). However, both action and speech can mutually elaborate each other (Goodwin 2000). Having access to materials also affects communication. When provided with physical materials, children can discuss abstract science phenomena such as evolution (Frejd 2018) and gravity (Schoultz et al. 2001). Moreover, when there is no shared scientific language, gestures and materials support students as their scientific language gradually develops (Roth and Lawless 2002). Both gestures and materials can thus be seen as shared semiotic resources (Van Leeuwen 2005) that enable students to both describe and explain - to do science.

\section{Context, Participants and Task}

Children from two preschool classes $(n=27)$ participated in the data collection. Swedish children attend preschool class during the year they turn 6 years old. The education is led by preschool teachers and combines social skills and free play with activities designed to stimulate children's curiosity and interest in literacy, mathematics and science (Skolverket 2017).

In this paper, the author designed and preformed the data collection and analysed the data. The author is also an experienced teacher. To gain mutual trust, she took part in both classes' ordinary work for a few days before the data collection commenced (Parkinson 2001).

The children were asked to discuss the following question: Lions, tigers, snow leopards and jaguars are all big cats. Several million years ago, all big cats looked alike. Why do they look so different from each other today? The question targets animal diversity and aimed to trigger scientific reasoning. A jaguar, lion, tiger and snow leopard were four big cats used as examples of speciation. These animals represent the same family (Felidae) and genus (Panthera). One reason for choosing big cats was that most children of this age have encountered these animals in books, television, movies or the zoo. As preparation for the group discussions, each child drew a picture of their idea and talked to the author about their ideas. Eight groups (3-4 children) were formed. Each of these contained a potential wide range of ideas, based on what the children had expressed in the preparation tasks. 
During the preparation tasks, and in the group discussions, the children had access to a topographic world map, photographs of the big cats in their natural habitats and figurines of the same animals. The figurines were initially placed in the location of their habitats at the beginning of each discussion. The materials were chosen since they resemble teaching materials frequently used in Swedish preschool classes (Fig. 1).

All eight discussions were videotaped with two cameras in order to capture gestures and handling of the materials. The discussions lasted for 10-25 min with an average time of 17 min.

The author facilitated each discussion by asking the children to elaborate upon their answers ("How do you mean?") and sometimes asked challenging questions to stimulate idea generation ("You say that the snow leopard is white since it lives in the snow and should not be seen; is it the same for the lion then?"). However, she did not correct or try to teach the children about evolutionary theory. Rather, the focus was on finding out more about the children's ideas and encouraging them to elaborate upon what they were saying. In relation to the performed analysis, it is also worth noting that the author wanted the children to discuss without her interfering. This approach is similar to that used in focus groups, in that the author aimed to maintain the focus on the interaction between the children, not an alternation between the author and the children (Morgan 1997).

This study follows the ethical guidelines stated by the Swedish Research Council (Gustafsson et al. 2006). The children's guardians and all participating children were informed about the study and its application, and all the children chose to take part in the activities. Guardians gave their consent in writing and the children orally.

\section{Analytical Process and Coding Schemes}

In this paper, four discussions are analysed in detail. These discussions were purposefully selected because they demonstrate a rich spectrum of interactional patterns during children's discussions about animal diversity. Moreover, the discussions differ in the number of turns during which the children stayed on task. In sum, the discussions analysed are representative of the variation in the collected data.

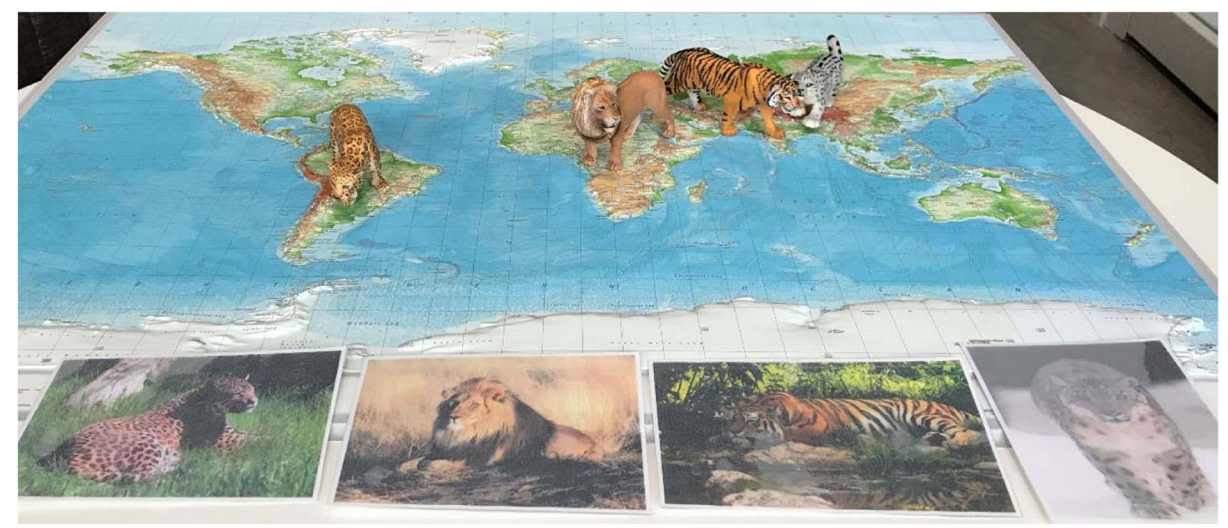

Fig. 1 Materials consisting of photographs of the big cats in their natural habitats, figurines and a topographic world map were provided in the discussions 
The group discussions were analysed in order to investigate both the nature of the interactions and acts of doing science. In doing so, three analytical questions provided a systematic approach that guided the analysis. The analytical questions were: What characterises the collaborative interactions in the discussions? What characterises acts of doing science in the discussions? and What relationships between acts of doing science and collaborative interactions can be identified in the discussions?

In correspondence with Hogan et al. (1999), codings were generated at two levels; namely, an interactional sequence level and a turn level. Codings made at a turn level capture actions restricted to one conversational turn. However, in order to interpret the character of the interaction, several turns need to be analysed as a whole. Thus, by coding at both levels, it is possible to discern a relationship between acts made at the turn level and the character of the interaction. In this paper, a turn is defined as beginning when a person started to talk, or performed some other communicative action, and ended when another person took the floor (Hogan et al. 1999). Interactional sequences are defined as a series of turns during which the same focus of discussion is maintained. An interactional sequence began when the discussion was refocused. Refocusing could occur through someone asking a question, presenting an idea, or doing other actions, such as reaching for or pointing at the materials. The interaction sequence ended when the discussion was refocused again (Hogan et al. 1999).

The following sections outline the sequence of analysis. An overview of the analytical procedures is presented in Table 1 .

\section{Step 1-Interactional Coding}

The first part of the coding procedure focused on the interaction in the discussions. This was performed in two ways. First, each turn was coded as informed by Hogan et al. (1999). Second, each interactional sequence was re-read and related to Granott's interaction model (Granott 1993).

\section{Statement Coding}

Hogan et al. (1999) present three main categories of statements that initiate, focus, sustain and deepen dialogue. These are conceptual statements, metacognitive statements, and questionqueries. In this paper, conceptual statements included: presenting ideas, providing information, elaborating upon what someone else had said and so on. Question-queries were used as one code, describing both direct questions for information (e.g. "Does the lion live in Africa?") and more query-like questions (e.g. "Where did the first tiger come from then?"). Metacognitive statements were of two types: regulatory, which directed the sequencing of the discussions ("Maybe I can start telling my idea") and evaluative. Evaluative statements were made in relation to a child's own idea, to a peer's idea, or to information provided. Codes in Hogan et al.'s scheme that were not applicable have been removed from the list of microcodes. ${ }^{1}$

In addition, two codes were added to the coding scheme. Turns during which the children talked or engaged in actions that were not related to the discussion about why animals look different were coded as Off task. The code Responds was added and applied to turns where the children or the author just responded to a question, without providing information or presenting an idea. A complete list of microcodes is presented in Table 2.

\footnotetext{
${ }^{1}$ Standard-based statements were not coded since the children did not reflect on standards.
} 


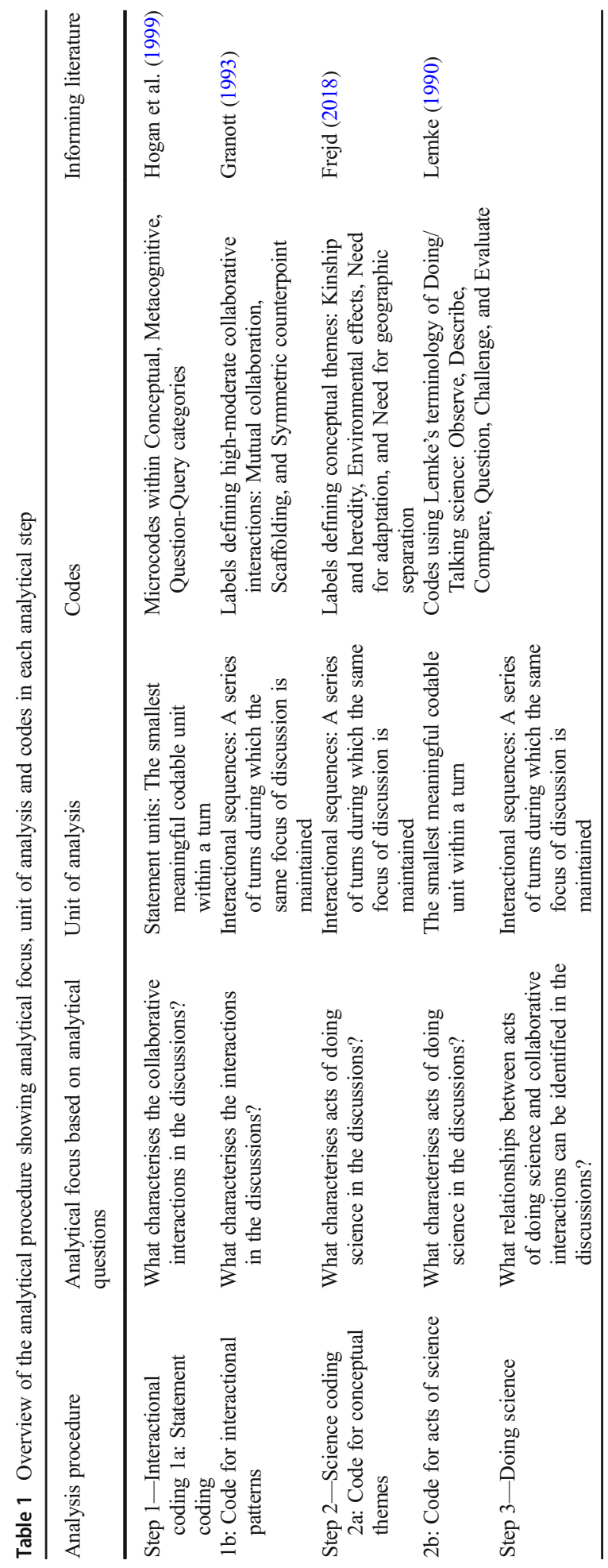


Table 2 List of microcodes, inspired by Hogan et al. (1999)

\begin{tabular}{ll}
\hline Statement category & Statement type \\
\hline Conceptual & Presents idea \\
& Presents partial idea \\
& Presents information \\
& Presents summary \\
& Repeats self \\
& Repeats other \\
& Elaborates upon self \\
& Elaborates upon other \\
& Evaluates own idea \\
& Evaluates other's idea \\
Metacognitive & Regulates action \\
& Presents query and/or asks for information \\
Question-query & Off task \\
Other & Responds \\
& \\
\hline
\end{tabular}

Turns in which the children were vague, played with words or expressed themselves in a way that was of no relevance to the discussion task at hand were not coded. The following excerpt is an example of turns that were not coded:

Author: You said that these animals were cousins?

Lisa: Yes

Joan: I said that (points at herself)

A: What do you mean... [To Laura] Yes, but then the others agreed.

In this example, the author wants the children to elaborate upon a previous idea about the animals being cousins. Joan's action where she points at herself as the initiator of this idea is not about the actual task-she does not talk about why the animals are different, nor is it off task - she is still talking about what has happened in the discussion.

The statement coding informed the next step of coding in two ways. First, it helped in defining interactional sequences (Hogan et al. 1999). Second, the statement categories, and the codes within each statement category, of each turn provided information on the character and distribution of turns among the participants.

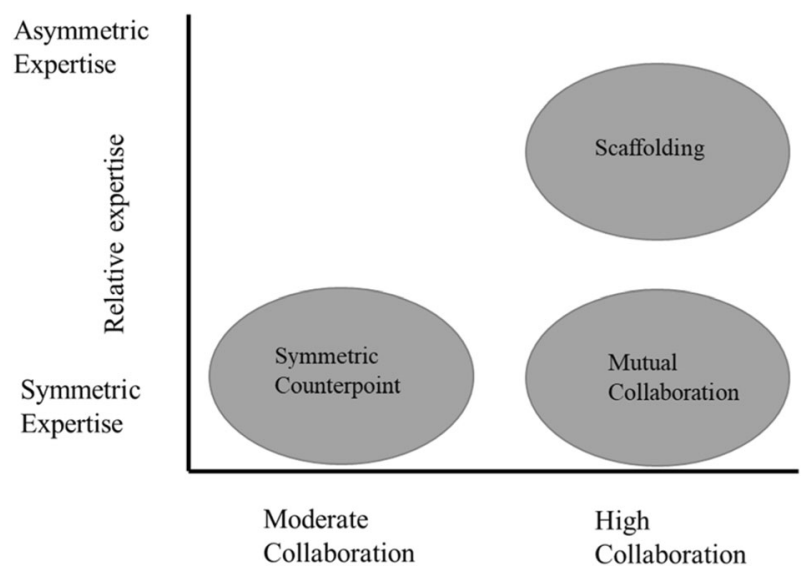

Fig. 2 Components of Granott's interaction model used to characterise the children's collaborative interactions (adapted from Granott 1993, p. 187) 


\section{Interactional Pattern Coding}

Next, the interactional coding procedure focused on collaborative interactions within the discussions. During this step, the units of analysis were interactional sequences (Hogan et al. 1999). Each discussion contained 4-13 interactional sequences.

The interactional sequences were related to Granott's interaction model (Granott 1993) in order to analyse and characterise the interactions. The model displays two major dimensions: Degree of interaction (moderate-high) and relative expertise between the participants (symmetric-asymmetric) (Fig. 2).

In highly collaborative interactions, mutual effort and sharing observations, materials, and ideas are essential. Highly collaborative interactions can be compared to sustained shared thinking (Sylva et al. 2004) where the interacting people all take active part in the meaningmaking. As shown in Fig. 2, both mutual collaboration and scaffolding interactions are highly collaborative. Mutual collaboration interactions are characterised by turns switching often and by the children following each other's reasoning. The verbal exchange is often intense, with abbreviated speech, simultaneous talk, and completing each other's sentences (Granott 1993). The author takes a passive role rather than actively taking part in the verbal exchange, even though she facilitates the discussion in the form of being an attentive listener. One example of mutual collaboration is provided below (Table 3).

In scaffolding interactions, the one with the greater expertise, for example the teacher (or, in this paper, the author), guides and assists the scaffold. For example, the author is directing observations and asking questions to make the child elaborate upon his/her ideas. Compared to mutual collaboration sequences, the author is more active in scaffolding interactions. In the following example of scaffolding, the author reminds the children of what they were talking about some time before, in order to redirect the discussion (Table 4).

Interactions with symmetric counterpoint are characterised by the participants being at the same knowledge level. As in mutual collaboration interactions, this means that the author is rather passive. Differing from mutual collaboration is the level of collaboration. In symmetric counterpoint, the children take turns to talk, while the others listen (Granott

Table 3 An example of a mutual collaboration sequence. The left-hand column shows the interactional space i.e. the turn. The two right-hand columns show the statement types generated by two participants (Hogan et al. 1999)

\begin{tabular}{|c|c|c|}
\hline Interactional space & Maria & Oscar \\
\hline $\begin{array}{l}\text { So, some of them (points at the map) were the same, all of them } \\
\text { have been the same... Like the lion (points at the lion figurine) }\end{array}$ & & Presents information \\
\hline In, back in the day & Presents information & \\
\hline Yes. A really... a really long time ago & & Elaborates other \\
\hline When we did not... & Elaborates other & \\
\hline At that time, there were no humans (looks at Maria) & & Elaborates other \\
\hline No & Agree & \\
\hline $\begin{array}{l}\text { And... (points from side to side with his index finger). } \\
\text { They maybe were in the same country back in the day }\end{array}$ & & Presents partial idea \\
\hline $\mathrm{Mmm}$ & Agree & \\
\hline And then some people caught them & & Elaborates self \\
\hline Yes & Agree & \\
\hline So they were in other countries & & Elaborates self \\
\hline $\mathrm{Mmm}$ & Agree & \\
\hline What do you think about that Ibrahim? & Requests information & \\
\hline
\end{tabular}


Table 4 An example of a scaffolding sequence. The column second to left shows the interactional space i.e. the turn. The left-hand column shows the author's statement types and the three right-hand columns show the statement types of each child (Hogan et al. 1999)

\begin{tabular}{|c|c|c|c|c|}
\hline Author & Interactional space & Maria & Oscar & Ibrahim \\
\hline \multirow[t]{3}{*}{ Question } & Have you come up with an explanation now then? & & & \\
\hline & No & & & Respond \\
\hline & (Shakes his head) No & & Respond & \\
\hline \multirow[t]{3}{*}{ Query } & $\begin{array}{l}\text { I thought you were on to something. You have } \\
\text { talked about them being of different size and } \\
\text { that their tails differentiate in length... }\end{array}$ & & & \\
\hline & (Nods) Yes & & Respond & \\
\hline & (Leans forward and looks at the figurines) & & & Uncodable \\
\hline \multirow[t]{3}{*}{ Query } & And then there was something about the food... & & & \\
\hline & Wait! (jerks) & & Uncodable & \\
\hline & Fish... & Repeats self & & \\
\hline \multirow{5}{*}{$\begin{array}{l}\text { Repeat } \\
\text { other }\end{array}$} & And fish & & & \\
\hline & $\begin{array}{l}\text { (Points at the jaguar figurine) It... } \\
\text { (points at the other figurines, but does not } \\
\text { say anything more) }\end{array}$ & & $\begin{array}{l}\text { Presents partial } \\
\text { idea }\end{array}$ & \\
\hline & Cod fish & $\begin{array}{l}\text { Presents } \\
\quad \text { information }\end{array}$ & & \\
\hline & $\begin{array}{l}\text { So (points at all the figurines) they kind } \\
\text { of eat the same thing }\end{array}$ & & $\begin{array}{l}\text { Presents partial } \\
\text { idea }\end{array}$ & \\
\hline & Yes, all of them eat meat & & & $\begin{array}{l}\text { Presents } \\
\text { information }\end{array}$ \\
\hline
\end{tabular}

1993). Consequently, they do not fill in sentences and it is not obvious that ideas are coconstructed.

\section{Step 2-Science Coding}

The science coding has been made in two ways. The first part of this coding served to investigate the conceptual aspects of the discussions i.e. how the children explained the reasons for animal diversity. The second part focused on acts of doing science informed by Lemke's (1990) terminology.

\section{Conceptual Theme Coding}

Aiming to look more closely at the conceptual dimension (Frejd (2018); Jaipal-Jamini 2011; Jaipal 2010) of science in the discussions, each interactional sequence was coded in line with the conceptual themes about underlying reasons for animal diversity proposed by Frejd (2018). This previous study revealed four qualitatively different themes of ideas when children (6 years old) talk about reasons for animal diversity; namely: Kinship and heredity, Environmental effects, Need for adaptation, and Need for geographic separation. Kinship and heredity concerns children's discussion of animal diversity as a result of breeding. The theme Environmental effects is characterised by reasoning that animals' appearances are instantly affected by something in the environment in which they live. For example, the children discuss that the lion is yellow since it has eaten yellow grass, or that the snow leopard's fur is white since it has been touched by snow. Need for adaptation contains a developmental aspect - the animals live in 
Table 5 Examples from the data illustrating the four conceptual themes (Frejd 2018

\begin{tabular}{|c|c|}
\hline Conceptual theme & Example from the data \\
\hline Kinship and heredity & Emma: Maybe one animal, a cat animal, gave birth to a lion \\
\hline Environmental effects & $\begin{array}{l}\text { Ibrahim: The snow leopard is a bit grey }(\ldots) \text { so it should have }(\ldots) \text { it was in the North } \\
\text { pole, and then... } \\
\text { Oscar: It loves snow } \\
\text { Ibrahim: Yes, and it bathed in a lake } \\
\text { Maria: In cold... } \\
\text { Oscar: Yes, in really cold water }\end{array}$ \\
\hline Need for adaptation & $\begin{array}{l}\text { Author: Why does the snow leopard has such thick fur? } \\
\text { Thomas: Because it's cold. It's really cold }\end{array}$ \\
\hline $\begin{array}{l}\text { Need for geographic } \\
\text { separation }\end{array}$ & $\begin{array}{l}\text { Thomas: (Places the lion on Greenland) No, you cannot come to me, it's cold! (Places } \\
\text { the lion on the Antarctic) I am freezing! He lives here now, he's going to live here. } \\
\text { Author: What would happen to it [the lion] if it lived there? } \\
\text { Thomas: It would become ice } \\
\text { Ellie: I think it would sleep or die }\end{array}$ \\
\hline
\end{tabular}

different environments and hence need different traits to survive. The theme Need for geographic separation lacks developmental aspects (see also Samarapungavan and Wiers 1997). Instead, animals are said to die instantly if there is a sudden change in the environment. Table 5 provides examples from the data representing each conceptual theme.

\section{Acts of Science Coding}

As a final step in the science coding procedure, each turn in the interactional sequences during which the children were discussing any of the conceptual themes were coded using Lemke's terminology (Lemke 1990). The acts coded for were Observe, Describe, Compare, Question, Challenge, and Evaluate. The act Discuss was not used as a code, since it is a general term and hard to identify at a turn level. The unit of analysis was the smallest meaningful codable unit within a turn. This coding was made in order to investigate acts of doing science in the group discussions. An example of steps 1 and 2 of the coding procedure is provided in the Appendix.

\section{Step 3-Doing Science}

Steps 1 and 2 of the analytical procedure provided insight into the character of the discussions and the expressed science content. In order to characterise relationships between acts of doing science and collaborative interactions, the codings were merged together as the final step of the analysis. First, focusing on one interactional sequence at a time, the codings of conceptual themes and collaborative interactions were linked to each other in each discussion. This meant that each interactional sequence was labelled both with the code for the conceptual theme discussed and the type of interactional collaboration within that particular sequence. Second, acts of doing science within the same interactional sequence were noted. Third, the number of turns spent on each interactional sequence was quantified. The number of turns off task and exploring materials without discussing the tasked question was also noted, since this might provide information about the character of the discussion as a whole. 


\section{Results}

The results are presented in correspondence with the three analytical questions. The results of the analysis are summarised in Table 6 and Fig. 3.

\section{Characteristics of the Interactions (Step 1)}

The analysis reveals that almost all the interactional sequences in the discussions are highly collaborative (Granott 1993). Out of the 22 interactional sequences where the children talk about the tasked question, 12 are carried out through mutual collaboration and nine are carried out through scaffolding. One sequence is characterised by symmetric counterpoint. One salient finding is that in all groups, the type of collaborative interaction switches between the interactional sequences. In other words, there is no discussion that is only carried out through one type of collaborative interaction. According to Granott (1993), a child can have one type of interaction with one peer, while having another type of interaction with another peer. In the discussions presented here, scaffolding interactions involve author-child communication, while the interactional sequences characterised by mutual collaboration contain a lot more child-child interaction. Still, both these types of interactions are highly collaborative. However, as shown in Table 6, one interactional sequence was coded as symmetric counterpoint, which is a moderate collaborative interaction (Granott 1993). This interactional sequence begins with Joan saying "The cat is cousin to all [of the animals]". The author repeats her statement verbatim and asks: "What do you others think of that?" The question is followed by the children, one at a time, pointing at the figurines, saying "This one is cousin to that one, and this one is cousin to that one...". Three of the four children do this, without stopping one another or filling in sentences. Instead, each turn begins with the speaking child saying "No" and then altering the order of pointing compared to the previous child. The question asked by the author ("What do you others think of that?"), is open-ended and posed to the whole group, which could have triggered the children's actions of speaking one at a time.

One thing that differs between the groups is the number of turns they spend on and off task (see Fig. 3). Maria, Ibrahim and Oscar's discussion and Thomas, Ellie, Harold and Anna's discussion are quite similar to each other. Both discussions are carried out through mutual collaboration and scaffolding. In addition, turns exploring the materials and being off task are quite similarly distributed between the two groups. The other two groups deviate from the rest. In Leah, Vanessa and Emma's discussion, all turns are on task. Table 6 displays that they did not only describe, observe and compare the materials. They also evaluated, questioned and (at one instance) challenged each other's ideas. Put differently, Leah, Vanessa and Emma were engaged in productive dialogue (Hogan et al. 1999). In addition, there are no interactional sequences in which they solely explore the materials without talking about why animals become different. In comparison, Joan, Michael, Nico and Lisa's discussion stands out in the small percentage of turns spent on actually talking about how animals become different. $85 \%$ of all turns are either off task or focusing on exploring and describing the materials in themselves. Compared to Leah, Vanessa and Emma, the dialogue here is less productive. This assumption is strengthened by that the discussion as a whole contain jokes, sarcasm and talk about other things than the posed question.

In sum, the groups' engagement in productive dialogue (Hogan et al. 1999) differs. However, the character of the interaction is similar when the children are on task. The 


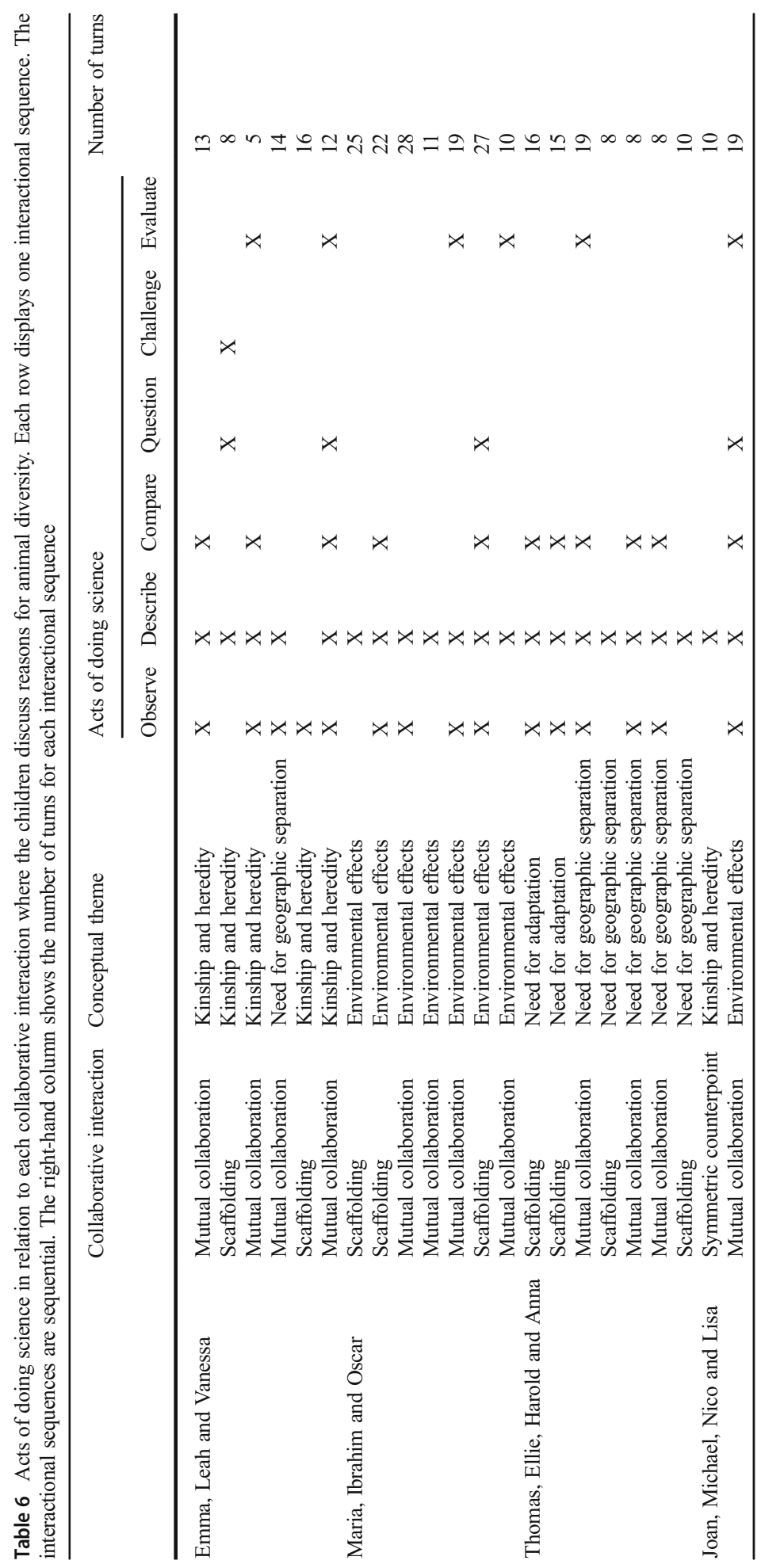




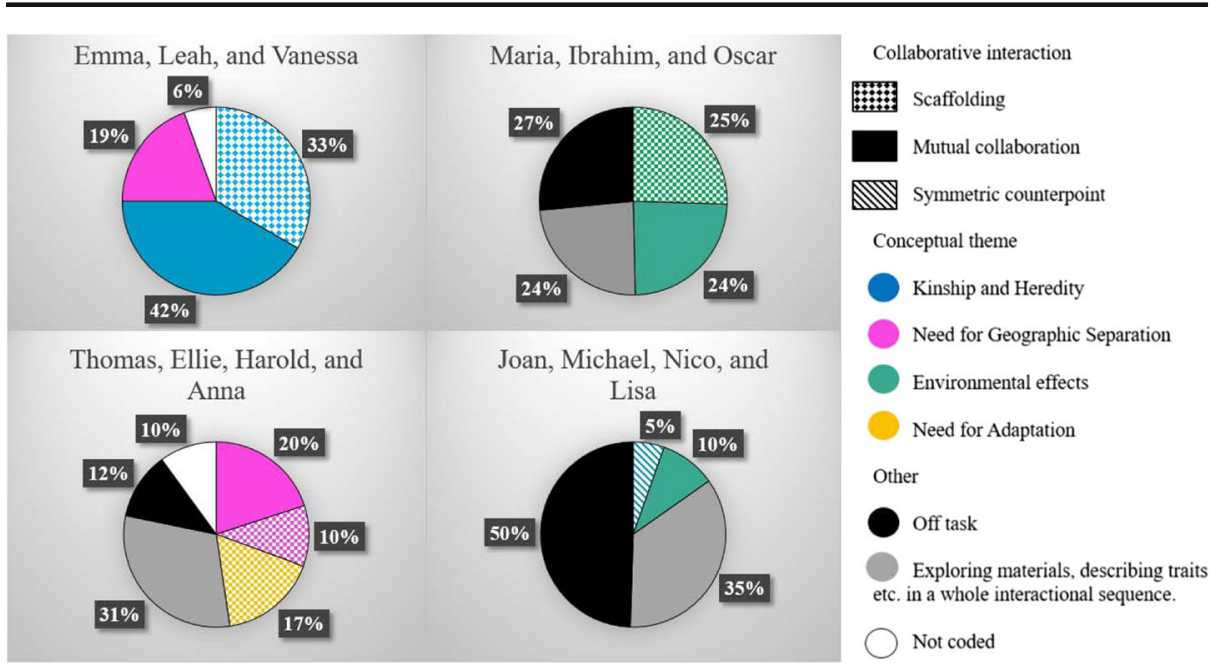

Fig. 3 Distribution of turns within each of the four discussions. Type of collaborative interaction is indicated by pattern. Conceptual theme is indicated by colour. The charts also include other turns that are off task (indicated by black colour), concern exploring materials and describing traits in a whole interactional sequence (indicated by grey colour), or not coded (indicated by white colour)

following section focuses on the conceptual dimension of doing science and how the children carry out acts of doing science.

\section{Identified Characteristics of Science Codings (Step 2)}

\section{Conceptual Themes}

In relation to the conceptual dimensions of doing science (Frejd 2018; Jaipal-Jamini 2011; Jaipal 2010), the four conceptual themes Kinship and heredity, Environmental effects, Need for adaptation and Need for geographic separation are discussed at some point (see Table 6 and Fig. 3). However, each group discusses a maximum of two themes. One group, Maria, Ibrahim and Oscar, only discusses animal diversity as the result of environmental effects. Nevertheless, there is no clear pattern between conceptual themes discussed and a specific type of collaborative interaction or act of doing science.

\section{Acts of Doing Science}

Table 6 displays a correlation between observing and comparing. All acts of comparing are preceded by an act of observation. The analysis thus shows that observations are used to compare traits as the children describe and argue for their ideas. One example of this appears in Leah, Vanessa and Emma's discussion. They discuss kinship and heredity as the reason to why animals are different. Their discussion is characterised by the children having quite clear, but contrasting, ideas. Vanessa argues that one animal gives birth to another, while Leah argues that the ancestors for each species originally came from eggs, which in turn came "from the ground" (please see Fig. 4 in the Appendix for a transcript from the discussion). The following example shows how Vanessa observes and compares the materials to describe her idea. 
In this example, Vanessa observes and compares the snow leopard's and the jaguar's patterns and detects similarities. This observation is used as evidence when she suggests that they might be mother and child. In these turns, we also see that the acts of doing science through observation, comparison and description elaborate the initial idea. In a similar way, the children observe, interpret and compare the different colours on the world map. In Joan, Michael, Lisa and Nico's discussion, such observations and comparisons are used to generate and describe the idea that animals become different as a result of what they eat in different environments (e.g. the snow leopard eats snow and thus becomes white). For example, they observe white fields on the map, interpret them as snow, and compare these with green fields, interpreted as a jungle.

The acts of questioning, challenging and evaluating are connected to each other in that they can be seen as indicating an objection to an idea. However, these acts are carried out quite differently. When the children question someone else, they do so by referring to their own assumptions. One example of this is when Joan says "I thought all of them ate meat" as a response to Michael's idea that animals become different because they eat different things. When the children challenge an idea, this is done by asking a challenging question. For example, when Emma suggests that the animals gave birth to one another, but never mentions who gave birth to the tiger, Leah challenges her idea by saying "But who gave birth to the tiger then?" As shown in Table 6, the act of challenging is very rare. The act evaluate is preceded by a child describing an idea, observation or comparison. Evaluations serve as either objections or confirmations of what their peer has described. When the children evaluate, they provide additional information to back up their objection or confirmation. In Leah, Vanessa and Emma's discussion, we see examples of both these variations (see Fig. 4 in the Appendix for the excerpt). Leah adds the information that offspring (jaguars) cannot give birth to parents (lions) (line 5) to her objection to Vanessa's idea that the jaguar is the parent of the lion. Emma, on the other hand, agrees with Vanessa's idea and hence adds information to support this (line 6) as she evaluates Leah's objection. Through this interaction and the acts of doing science, the ideas are developed and elaborated.

Table 6 shows that, when children evaluate ideas, the interactional sequence also includes acts of observing and/or comparing. Just one interactional sequence deviates from this pattern. This is when Oscar evaluates his own previously proposed idea that snow leopards might eat penguins and then says that penguins do not live where snow leopards live. This idea is based on prior experience, and not on observations made in the discussion.

Going back to the example where Michael suggests that animals become different as an effect of what they have eaten, this idea is based on observation and comparison of the materials. However, Joan's evaluation, "I thought all of them ate meat", can be seen as an expression of prior experience of what big cats usually eat. In sum, the idea that was generated by one child, through observation and comparison, was evaluated by a peer based on her prior experience. The analysis thus reveals that prior experiences seem to enable the children to make observations and to evaluate ideas. Nevertheless, prior experiences also seem to matter in the combined acts of observation and comparison. One example of this is provided in Excerpt 1. Vanessa's observation and comparison of the materials serve to qualify her idea that animals that are alike should be closely related. However, the idea that animals that are related look-alike is most likely based on prior experiences.

In sum, acts of doing science are carried out in several ways. By using their prior experiences and the materials, the children carry out acts of doing science both to present, 

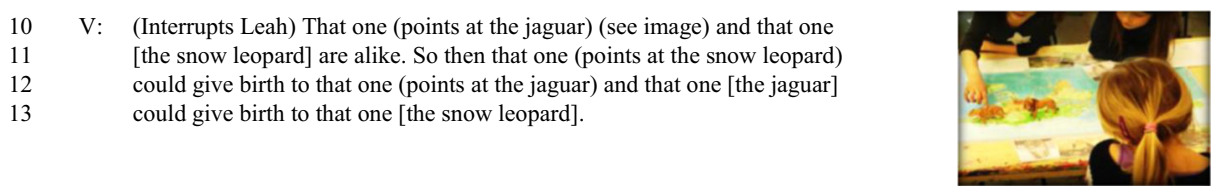

Excerpt 1 Example of observing, comparing and describing. The right-hand column provides a screenshot from the discussion. A longer transcript containing turns before and after this excerpt is provided in Fig. 4 in the Appendix

evaluate and reject ideas. In addition, acts of doing science in interaction elaborate and extend ideas. The following section displays the analysis of the relationships between acts of doing science and collaborative interactions.

\section{Doing Science (Step 3)}

In line with Hogan et al. (1999), the findings show that the groups differed in their productive dialogue during the discussions (see Fig. 3). One group-Leah, Vanessa and Emma - stayed on task for the whole discussion. In that group, all the different acts of doing science: describe, observe, compare, evaluate, question and challenge (Lemke 1990), were present at least once. One salient feature that characterised this discussion was that the children had clear, but contrasting, ideas. In trying to convince each other that their respective ideas were valid, they used observations and comparisons along with their prior experiences. In addition, they questioned and challenged each other and evaluated ideas and observations.

Two groups-Maria, Ibrahim and Oscar's group and the group with Thomas, Ellie, Harold, and Anna - spent similar time talking about the tasked question. Moreover, the groups are similar in that the interaction is almost equally carried out through mutual collaboration and scaffolding. Maria, Ibrahim and Oscar's discussion is characterised by the children observing and comparing traits and using their observations to describe differences and similarities among traits. There is one instance of evaluation. However, this is a single instance when Oscar evaluates his own previously proposed idea that snow leopards might eat penguins. Later in the discussion, he evaluates this by saying "But the snow leopard lives there (points at the Himalayas) ... Penguins don't live there”. Thomas, Ellie, Harold and Anna discuss the idea that animals are adapted to the environment they live in (e.g. the lion needs to have great distance vision to be able to catch prey on the savannah). They also discuss the idea that individual species cannot live everywhere (e.g. the lion would freeze to death if it lived in the Antarctic). As Maria, Ibrahim and Oscar, Thomas, Ellie, Harold and Anna observe and compare traits and use their observations to describe differences and similarities among traits. Moreover, they use prior experiences and analogies to underpin the idea that snow leopards might sleep during the winter "in the same way that bears do".

Joan, Michael, Nico and Lisa spent $85 \%$ of their turns off task or solely exploring the material (see Fig. 3). However, one of their two interactional sequences contains several acts of doing science. In 19 turns carried out through mutual collaboration (10\% of the total amount of turns in the discussion), the children do science through the acts of describing, observing, comparing, questioning and evaluating (see Table 6). This could indicate that mutual collaboration, even in small proportions within a discussion, correlates with children doing science. 
Moreover, the analysis shows a relationship between interacting through mutual collaboration and doing science in terms of questioning and challenging ideas (see Table 6). Looking at the groups as a whole, five out of 12 mutual collaboration interactions contain questioning or challenging. In scaffolding interactions, these acts of doing science occur in two out of nine sequences. In addition, there seems to be a correlation between evaluating ideas and interacting through mutual collaboration. In fact, all evaluating actions are made within mutual collaboration sequences. One salient finding thus is that the character of the discussion seems to affect what acts of doing science are carried out.

The relationship between mutual collaboration and multiple acts of doing science indicates that doing science is supported by collaborative acts and social processes (Siry et al. 2012). The following section provides a discussion of the relationships between acts of doing science and collaborative interactions.

\section{Discussion}

The aim of this study was to explore how children do science when they discuss the underlying reasons for animal diversity, and to characterise the relationships between acts of doing science and collaborative interactions.

In all groups, the most frequent acts of doing science were describing, observing and comparing. These acts are related to each other and the materials played a central role. Thus, this study confirms the notion that interaction with materials is an important part of doing science (Ash 2004). As shown, all acts of comparison were preceded by an act of observation, which suggests that having the possibility to observe differences and similarities in materials enables children to make comparisons. Moreover, the materials provided for the children served as tools for thinking and hence influenced what the children were able to describe and discuss (Frejd 3; Schoultz et al. 2001).

The findings of this study reveal that the child-child interaction supports and enriches ideas when acts of doing science are carried out. More specifically, the analysis shows that children in this particular context evaluate, question and challenge each other's ideas. This observation reveals that children as young as 6 years old are able to engage in science dialogue that is not merely descriptive. This is an intriguing result since previous studies have shown that descriptions predominate in science classroom dialogue (Ødegaard et al. 2016). When children question, evaluate or challenge a peer's ideas, they do so by using their own prior experiences combined with observations of the provided materials. The act of evaluation in this particular context occurred as a responsive act, to express either agreement or disagreement. Evaluations were characterised by children providing additional information, based on observations or prior experiences, to support their objection or agreement. Previous research has shown that prior experience influences what is observed (Kohlhauf et al. 2011). In this regard, Kohlhauf et al. mean that "The more we know about the object or process observed, the more research questions and hypotheses seem to be created in our thoughts" (p. 675). However, the findings of this paper have shown that both situated acts of doing science, namely observing and comparing, and prior experiences are important when children discuss ideas.

Collaborative work is an important part of doing science and working in small groups enables children to share ideas (e.g. Granott 1998). The findings of this study reveal that the situated context and character of the collaborative interactions also seem to be important for what science acts become visible in the discussions. More specifically, the analysis shows a 
relationship between interacting through mutual collaboration and doing science in terms of evaluating, questioning, and challenging ideas. Just considering the acts of doing science, the discussion is more complex (i.e. involves more acts) in sequences carried out through mutual collaboration compared to scaffolding sequences. In collaborative interactions characterised by mutual collaboration, children engage in productive dialogue (Hogan et al. 1999) about the reasons for animal diversity.

One difference between interactions characterised by mutual collaboration and scaffolding is the author's role and the dialogue between peers. In sequences involving mutual collaboration, the author is less active and engages more in attentive listening than in sequences with scaffolding, where the author more actively engages in the dialogue. In mutual collaboration interactions, the children observe and compare materials, on their own and in collaboration with each other, and use these observations to generate and evaluate ideas. In a previous study by Hsin and Wu (2011), the researchers argue that teachers should scaffold children in how they should perceive materials in order to enhance their understanding of floatation. However, this study suggests that teachers taking the role of an attentive listener could enable aspects of science other than conceptual to emerge. In relation to doing science, the results indicate that children's collaborative interaction enables acts of doing science to become both practised and visible. Moreover, excessive scaffolding could limit some acts of doing science. Nevertheless, the teacher's role in young students' small-group discussions needs to be further explored.

The four groups presented in this work demonstrate various levels of engagement in the discussions. Having contrasting ideas seems to be one explanation for high levels of engagement. However, going into the group discussion activity, all groups were formed based on the criteria that the children had expressed differing ideas in the preparatory tasks. The fact that some groups spent more turns off task than others could reflect their interest in the task or the social structures of the group. It is possible that using another science phenomenon rather than animal diversity as the topic for discussion would have affected the engagement. Moreover, access to other materials might affect both the engagement and the acts of doing science carried out in the discussions.

Siry et al. (2012) state that children engaged in science-related practices show an awareness of doing science as they "collaboratively orient to a specific format for completing the activity" (p. 320). By building on literature arguing that discussion and argumentation are part of science culture (Osborne 2010), this paper demonstrates that children do science when engaged in science-related discussions. However, we still need to know more about how children engage in doing science in various contexts. Future work will further explore how creative group activities and narratives influence how children do science.

In conclusion, this paper has shown that children as young as 6 years old indeed do science when engaged in science-related discussions. Moreover, the analysis show that children's productive dialogue and acts of doing science increase within interactions characterised by mutual collaboration and the teacher takes the role of an attentive listener. Implementing group discussions as means to encounter science is a fruitful way to improve early childhood education.

\section{Compliance with Ethical Standards}

Conflict of Interest The author declares that there is no conflict of interest. 


\section{Appendix}

The following example serves to illustrate steps 1 and 2 of the analytical procedure. The example provides a detailed description of the character of the discussion and how the children carry out acts of doing science. Screenshots from the video show examples of the multimodal interaction obtained when acts of doing science were carried out in the discussion. Reference numbers are given in the transcript to each picture. Gestures and bodily actions are described in parentheses and simultaneous talk is shown by the use of the "[" symbol in the left-hand margin (Fig. 4).

In this excerpt, Vanessa, Leah, and Emma discuss the idea that animals are different as a result of breeding, which is part of the conceptual theme kinship and heredity. The interactional sequence is characterized by the children being engaged in the discussion. This is demonstrated in several ways. First, the children fill in each other's sentences. For example, Emma elaborates that the egg Leah talks about is "big" (line 18). Second, they follow each other's reasoning. One example of this is when Leah quickly reacts and responds (line 5) to what Vanessa has said about the lion being the joint ancestor. Hence, the interactional sequence is seen as an example of mutual collaboration (Granott 1993).

Moreover, the sequence is characterized by the children having quite clear, but contrasting, ideas. Vanessa argues that one animal gives birth to another (lines 1-4), while Leah argues that the ancestors for each species originally came from eggs, which in turn came "from the ground" (lines 15-17). That the children have such contrasting ideas could be triggering the act of questioning. Nevertheless, all three are listening actively and seem to be trying to understand each other. One example of this is provided at the end of the sequence (lines 23-26), when Vanessa synthesizes her own and Leah's idea into one idea that combines the two. The

\begin{tabular}{|c|c|c|c|c|c|}
\hline $\begin{array}{l}\text { Line } \\
\text { Nr. }\end{array}$ & $\begin{array}{l}\text { Child's } \\
\text { name }\end{array}$ & Discussion & $\begin{array}{l}\text { Acts of } \\
\text { doing } \\
\text { science }\end{array}$ & & Images \\
\hline $\begin{array}{l}1 \\
2 \\
3 \\
4\end{array}$ & Vanessa: & $\begin{array}{l}\text { Maybe it was one of these big animals (points at the lion) that was first and were in all countries, except in } \\
\text { Sweden, and then that one (points at the lion) gave birth to that one (points at the jaguar) (1), } \\
\text { and that one [the jaguar] gave birth to that one [the lion] and that one [the jaguar] gave birth } \\
\text { to that one [the snow leopard] and that one [the snow leopard] gave birth to that one [the jaguar]. }\end{array}$ & Describe & 1 & \\
\hline 5 & Leah: & But this is a dad (points at the lion) (2), so it [the jaguar] cannot have given birth to that one [the lion]. & $\begin{array}{l}\text { Question, } \\
\text { Evaluate }\end{array}$ & & \\
\hline 9 & L: & But then... & & & \\
\hline $\begin{array}{l}10 \\
11 \\
12\end{array}$ & $\mathrm{v}$ : & $\begin{array}{l}\text { (Interrupts Leah) That one (points at the jaguar) (4) and that one [the snow leopard] are alike. So then that } \\
\text { one (points at the snow leopard) could give birth to that one (points at the jaguar) and that one [the jaguar] } \\
\text { could give birth to that one [the snow leopard]. }\end{array}$ & $\begin{array}{l}\text { Observe, } \\
\text { Compare, } \\
\text { Describe }\end{array}$ & 3 & \\
\hline 13 & L: & (interrupts Vanessa) But this one (touches the snow leopard figurine) maybe came up here... & Describe & & \\
\hline 18 & $\mathrm{E}:$ & A big egg. & Describe & & \\
\hline 19 & L: & Yes, an egg big as this one (points at a painting with a big Easter egg) (6). & Describe & & \\
\hline 20 & $\mathrm{E}$ and $\mathrm{V}$ : & (Looks at the painting) & & & \\
\hline $\begin{array}{l}21 \\
22\end{array}$ & Author: & $\begin{array}{l}\text { How do you think that sounds, Vanessa? That there is a giant egg somewhere... The first cats comes from } \\
\text { big eggs. }\end{array}$ & & 5 & \\
\hline $\begin{array}{l}23 \\
24\end{array}$ & $\mathrm{v}:$ & $\begin{array}{l}\text { That there was an egg from some kind of animal on the ground (makes a gesture as though she is grasping } \\
\text { an egg from the map) (7), and then it hatched and it was some other type of animal. }\end{array}$ & Describe & & \\
\hline $\begin{array}{l}25 \\
26\end{array}$ & & $\begin{array}{l}\text { Maybe this (points at the snow leopard figurine) was in an egg, and then hatched and it became like this } \\
\text { and then it gave birth to cubs. }\end{array}$ & & 6 & \\
\hline
\end{tabular}

Fig. 4 Excerpt 2 Vanessa, Leah, Emma, and the interviewer. Acts of doing science are presented in the column second from the right. The right-hand column provides screenshots from the discussion 
synthesized idea expressed is that the first ancestor might have come from an egg, but that this individual then gave birth to the other animals.

The acts of doing science that are present in this interactional sequence are observe, describe, compare, question, and evaluate. The children continuously describe their ideas, both with verbal language and by using bodily actions. In lines 17 (image 4) and 19 (image 5), we see how Leah uses both gestures and a painting to describe the idea that big cats originate from big eggs.

The children make observations of the materials and compare traits. One example of this is found in lines 10-12 and 14, when Vanessa observes and compares the materials and detects similarities in the snow leopard's and the jaguar's patterns. This observation is used as evidence when she suggests that they might be mother and child. In these turns we also see that the interaction and the acts of doing science elaborates the initial idea.

In line 5, Leah questions and evaluates Vanessa's idea. It seems as though Leah's evaluation is based on her observation and comparison of the material - the materials show that the four big cats differ in size - and her previous experience of parents being bigger than their children. Moreover, in line 6, Emma responds to Leah and evaluates her inference by saying that the jaguar could be "a mum." This is interpreted as though Emma means that even if the lion is "a dad," dads also have mothers. In these lines, the acts of doing science support and enrich the idea that animals are different as a result of breeding. The interaction thus also can be seen as an example of sustained shared thinking (Sylva et al. 2004).

The analysis of Excerpt 2 shows that children carry out various acts of doing science when, through mutual collaboration, they discuss animal diversity as a result of breeding. In addition, we see that the acts carried out are often made in relation to the materials.

Open Access This article is distributed under the terms of the Creative Commons Attribution 4.0 International License (http://creativecommons.org/licenses/by/4.0/), which permits unrestricted use, distribution, and reproduction in any medium, provided you give appropriate credit to the original author(s) and the source, provide a link to the Creative Commons license, and indicate if changes were made.

Publisher's Note Springer Nature remains neutral with regard to jurisdictional claims in published maps and institutional affiliations.

\section{References}

Andersson, K., \& Gullberg, A. (2014). What is science in preschool and what do teachers have to know to empower children? Cultural Studies of Science Education, 9(2), 275-296.

Ash, D. (2004). Reflective scientific sense-making dialogue in two languages: the science in the dialogue and the dialogue in the science. Science Education, 88(6), 855-884.

Frejd, J. (2018) "If It Lived Here, It Would Die." Children's Use of Materials as Semiotic Resources in Group Discussions About Evolution. Journal of Research in Childhood Education, 32(3), 251-267.

Fleer, M. (2017). Scientific playworlds: a model of teaching science in play-based settings. Research in Science Education, 1-22.

Gallas, K. (1995). Talking their way into science: hearing children's questions and theories, responding with curricula. New York: Teachers College Press.

Goodwin, C. (2000). Action and embodiment within situated human interaction. Journal of Pragmatics, 32, $1489-1522$.

Granott, N. (1993). Patterns of interaction in the co-construction of knowledge: separate minds, joint effort, and weird creatures. In R. H. Wozniak \& K. W. Fisher (Eds.), Development in context: acting and thinking in specific environments (pp. 183-207). Hillsdale, NJ: Erlbaum.

Granott, N. (1998). Unit of analysis in transit: from the individual's knowledge to the ensemble process. Mind, Culture, and Activity, 5(1), 42-66. 
Gustafsson, B., Hermerén, G., \& Petersson, B. (2006). Good research practice - what is it?: views, guidelines and examples: Stockholm : Vetenskapsrådet, 2006.

Herakleioti, E., \& Pantidos, P. (2016). The contribution of the human body in young children's explanations about shadow formation. Research in Science Education, 46(1), 21-42. https://doi.org/10.1007/s11165-014-9458-2.

Hogan, K., Nastasi, B. K., \& Pressley, M. (1999). Discourse patterns and collaborative scientific reasoning in peer and teacher-guided discussions. Cognition and Instruction, 17(4), 379-432.

Howitt, C., Upson, E., \& Lewis, S. (2011). 'It's a mystery!': a case study of implementing forensic science in preschool as scientific inquiry. Australasian Journal of Early Childhood, 36(3), 45.

Hsin, C.-T., \& Wu, H.-K. (2011). Using scaffolding strategies to promote young children's scientific understandings of floating and sinking. Journal of Science Education and Technology, 20(5), 656-666. https://doi. org/10.1007/s10956-011-9310-7.

Jaipal-Jamini, K. (2011). A semiotics discourse analysis framework: understanding meaning making in science education contexts. In S. C. Hamel (Ed.), Semiotics theory and applications (pp. 191-208). New York: Nova Science Publishers, Inc..

Jaipal, K. (2010). Meaning making through multiple modalities in a biology classroom: a multimodal semiotics discourse analysis. Science Education, 94(1), 48-72.

Jewitt, C. (2011). The routledge handbook of multimodal Analysis. London and New York: Routledge.

Jewitt, C., Kress, G., Ogborn, J., \& Tsatsarelis, C. (2001). Exploring learning through visual, actional and linguistic communication: the multimodal environment of a science classroom. Educational Review, 53(1), 5-18.

Jimenez-Aleixandre, M. P., Rodriguez, A. B., \& Duschl, R. A. (2000). "Doing the lesson" or "doing science": argument in high school genetics. Science Education, 84(6), 757-792.

Kohlhauf, L., Rutke, U., \& Neuhaus, B. (2011). Influence of previous knowledge, language skills and domainspecific interest on observation competency. Journal of Science Education and Technology, 20(5), 667-678. https://doi.org/10.1007/s10956-011-9322-3.

Kolstø, S. D., \& Ratcliffe, M. (2008). Social aspects of argumentation. In S. Erduran \& M. P. Jiménez-Aleixandre (Eds.), Argumentation in science education (pp. 117).

Kress, G., \& van Leeuwen, T. (2006). Reading images: the grammar of visual design (2 ed.). London: Routledge.

Larsson, J. (2013). Contextual and conceptual intersubjectivity and opportunities for emergent science knowledge about sound. International Journal of Early Childhood, 45(1), 101-122.

Lemke, J. L. (1990). Talking science: language, learning, and values. In. Norwood, New Jersey: Ablex Publishing Coporation.

Morgan, D. L. (1997). Focus groups as qualitative research (2nd ed., [rev.] ed ed.). Thousand Oaks, CA: Sage.

Mueller, M. F. (2009). The co-construction of arguments by middle-school students. The Journal of Mathematical Behavior, 28(2-3), 138-149.

Murphy, C., Murphy, C., \& Kilfeather, P. (2011). Children making sense of science. Research in Science Education, 41(2), 283-298. https://doi.org/10.1007/s11165-010-9165-6.

Naylor, S., Keogh, B., \& Downing, B. (2007). Argumentation and primary science. Research in Science Education, 37(1), 17-39.

Osborne, J. (2010). Arguing to learn in science: the role of collaborative, critical discourse. Science, 328(5977), $463-466$.

Parkinson, D. D. (2001). Securing trustworthy data from an interview situation with young children: six integrated interview strategies. Child Study Journal, 31(3), 137-156.

Roth, W.-M. (2005). Talking science: language and learning in science classrooms. Lanham, MD: Rowman \& Littlefield Publishers.

Roth, W.-M., \& Lawless, D. (2002). Science, culture, and the emergence of language. Science Education, 86(3), 368-385.

Samarapungavan, A., \& Wiers, R. W. (1997). Children's thoughts on the origin of species: a study of explanatory coherence. Cognitive Science, 21(2), 147-177.

Schoultz, J., Säljö, R., \& Wyndhamn, J.-O. (2001). Heavenly talk: discourse, artifacts, and children's understanding of elementary astronomy. Human Development, 44(2-3), 103-118.

Siry, C., Ziegler, G., \& Max, C. (2012). "Doing science" through discourse-in-interaction: young children's science investigations at the early childhood level. Science Education, 96(2), 311-336.

Skolverket. (2017). Läroplan för grundskolan, förskoleklassen och fritidshemmet 2011: Reviderad 2017 (curriculum for the compulsory school, preschool class and the recreation centre, 2011: revised 2017). Stockholm: Skolverket.

Sylva, K., Melhuish, E., Sammons, P., Siraj-Blatchford, I., \& Taggart, B. (2004). The Effective Provision of PreSchool Education (EPPE) Project: findings from pre-school to end of key stage 1. Retrieved from https://www.ucl.ac.uk/ioe/sites/ioe/files/RB_Final_Report_3-7.pdf:

Van Leeuwen, T. (2005). Introducing social semiotics. London: Routledge. 
Yoon, J., \& Onchwari, J. A. (2006). Teaching young children science: three key points. Early Childhood Education Journal, 33(6), 419-423. https://doi.org/10.1007/s10643-006-0064-4.

Ødegaard, M., Arnesen, N. E., \& Klette, K. (2016). Talk and use of language in the science classroom: characteristic features. In K. Klette, O. K. Bergem, \& A. Roe (Eds.), Teaching and learning in lower secondary schools in the era of PISA and TIMSS (pp. 101-112): Springer. 